\title{
Effects of Lanthanum(III) on Copper(II) stressed rice (Oryza sativa) and its molecular mechanism revealed by transcriptome profiling
}

\author{
Yuqing Zhong ${ }^{1}$ and Jiajia Chen ${ }^{1}$ \\ ${ }^{1}$ Suzhou University of Science and Technology
}

May 5, 2020

\begin{abstract}
Rare earth elements are known to alleviate heavy metal stress. However, the potential mechanisms of alleviation remain unclear. This study compared the effects of $\mathrm{La}(\mathrm{NO} 3) 3$ and $\mathrm{La}(\mathrm{NO} 3) 3$-amino acid chelates (La(III)-AA) on growth, oxidative stress, ultrastructure, bioaccumulation and gene expression in rice. Results demonstrated that $20 \mathrm{mg} / \mathrm{L} \mathrm{La(III)-AA} \mathrm{can} \mathrm{effectively}$ ameliorate $\mathrm{CuSO} 4(50 \mathrm{mg} / \mathrm{L})$ stress in rice by reducing oxidative stress and increasing chlorophyll content, thus promoting growth. ICP and TEM revealed an antagonistic effect between $\mathrm{La}(\mathrm{III})$ and $\mathrm{Cu}$ (II). Exogenous $\mathrm{La}$ (III)-AA decreased $\mathrm{Cu}$ (II) content in rice leaves, stems and roots by $55.56 \%, 59.46 \%$ and $26.29 \%$, and ameliorated $\mathrm{Cu}$ (II) damage by maintaining the ultrastructure of mesophyll cells. RNA sequencing identified 7020 differentially expressed genes, and 8 were validated by qRTPCR. Indole-3-acetic acid (IAA) concentration was detected by HPLC. Correlation analysis between OsGH3.4-IAA-Expansin revealed that IAA content is negatively correlated with OsGH3.4 ( $\mathrm{r}=-0.82, \mathrm{P}<0.05)$, and positively correlated with Expansin $(\mathrm{r}=0.78, \mathrm{P}<0.05)$. It's assumed that La(III)-induced OsGH3.4 could inhibit IAA-dependent Expansin expression, thereby conferring resistance to $\mathrm{Cu}$ stress. This work provides novel insights into the molecular basis underlying La-induced Cu tolerance in rice.
\end{abstract}

\section{Hosted file}

Main document.doc available at https://authorea.com/users/300610/articles/430316-effectsof-lanthanum- $\%$ E2\%85\%B2-on-copper-\%E2\%85\%B1-stressed-rice-oryza-sativa-and-its-molecularmechanism-revealed-by-transcriptome-profiling 


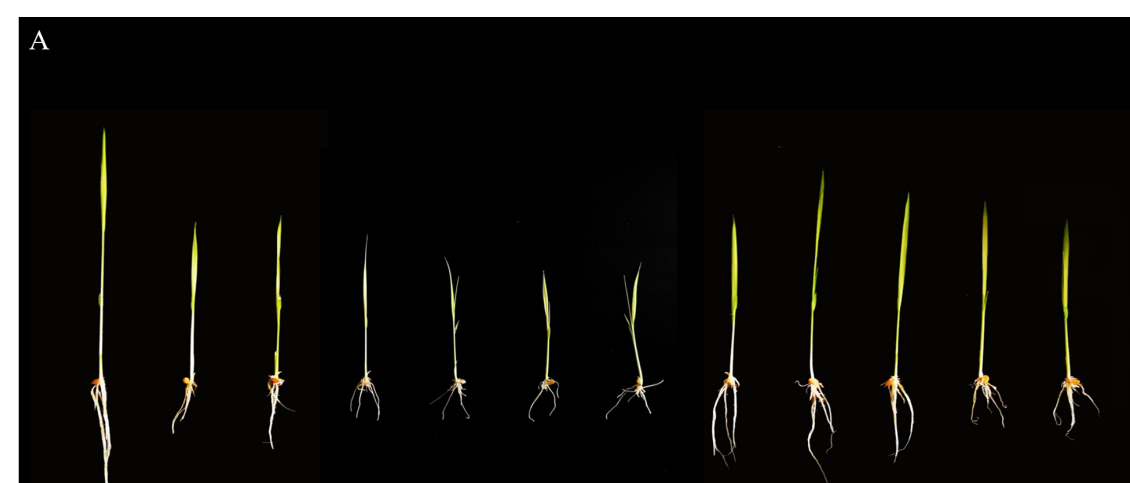

$50 \mathrm{mg} / 1 \quad 10 \mathrm{mg} / 1 \quad 20 \mathrm{mg} / 1 \quad 30 \mathrm{mg} / 1 \quad 40 \mathrm{mg} / 1 \quad 50 \mathrm{mg} / 1 \quad 10 \mathrm{mg} / 1 \quad 20 \mathrm{mg} / 1 \quad 30 \mathrm{mg} / 1 \quad 40 \mathrm{mg} / 1 \quad 50 \mathrm{mg} / 1$

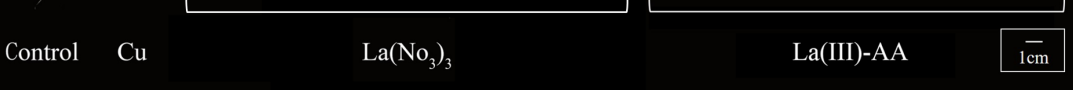

B
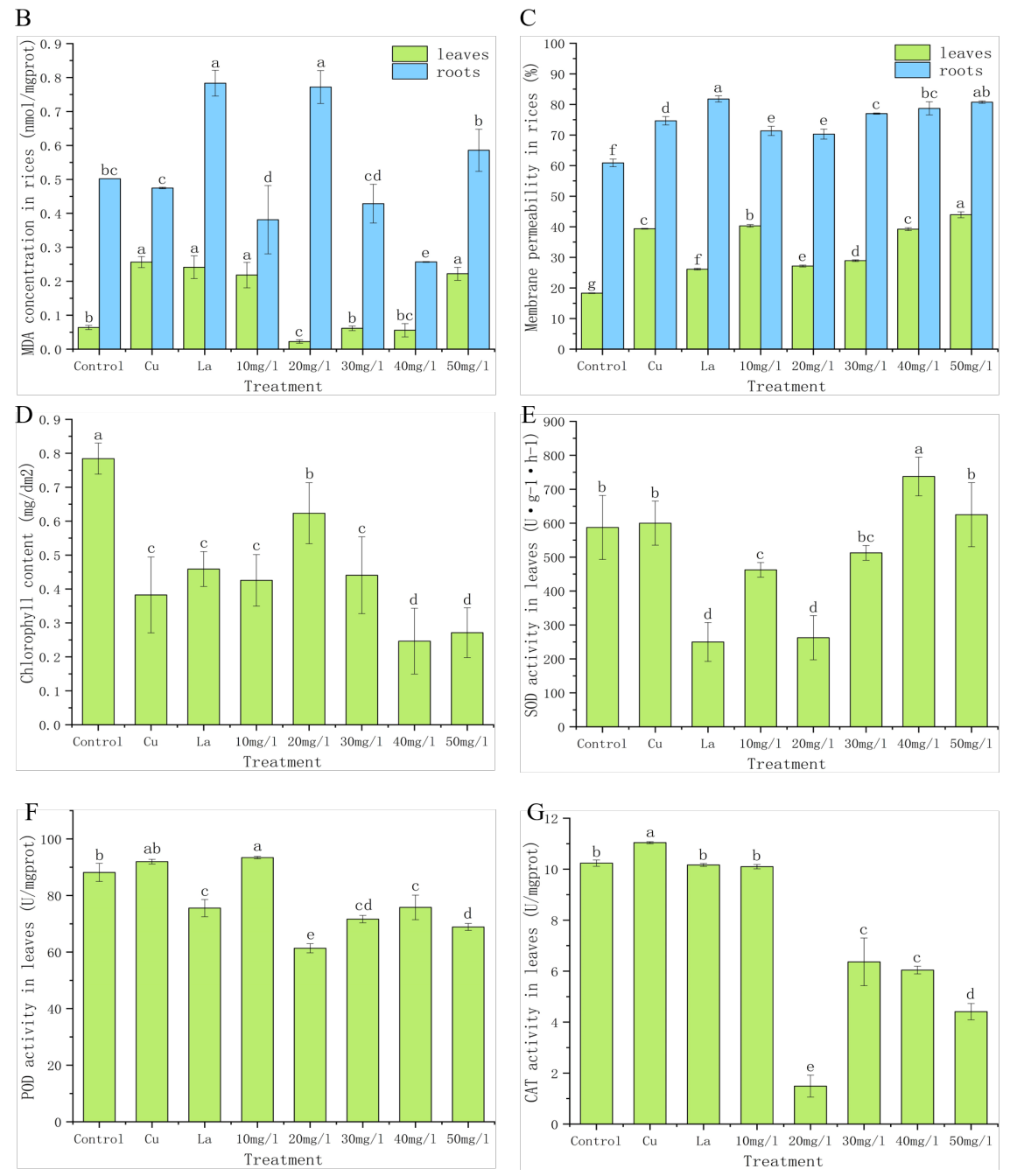

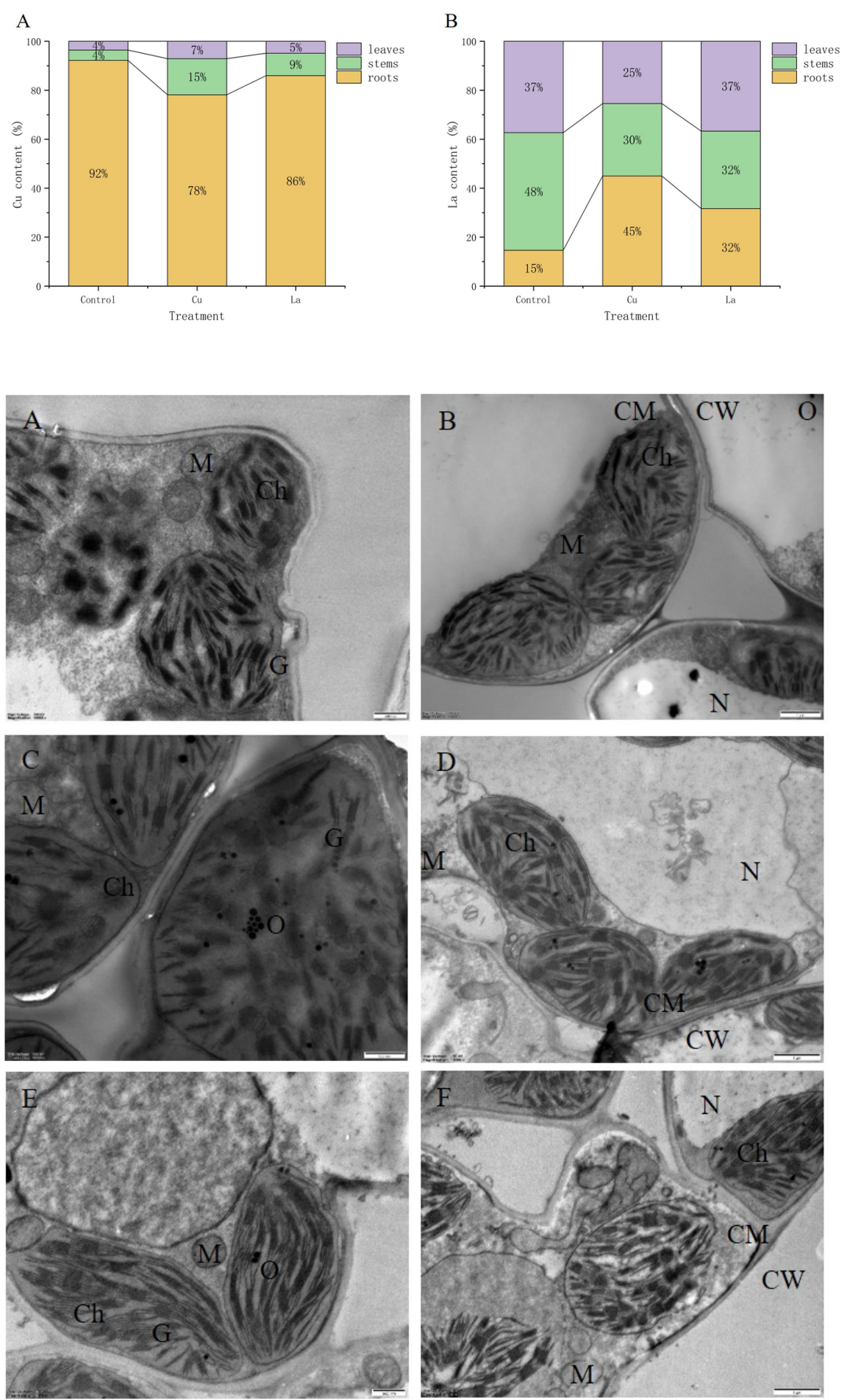


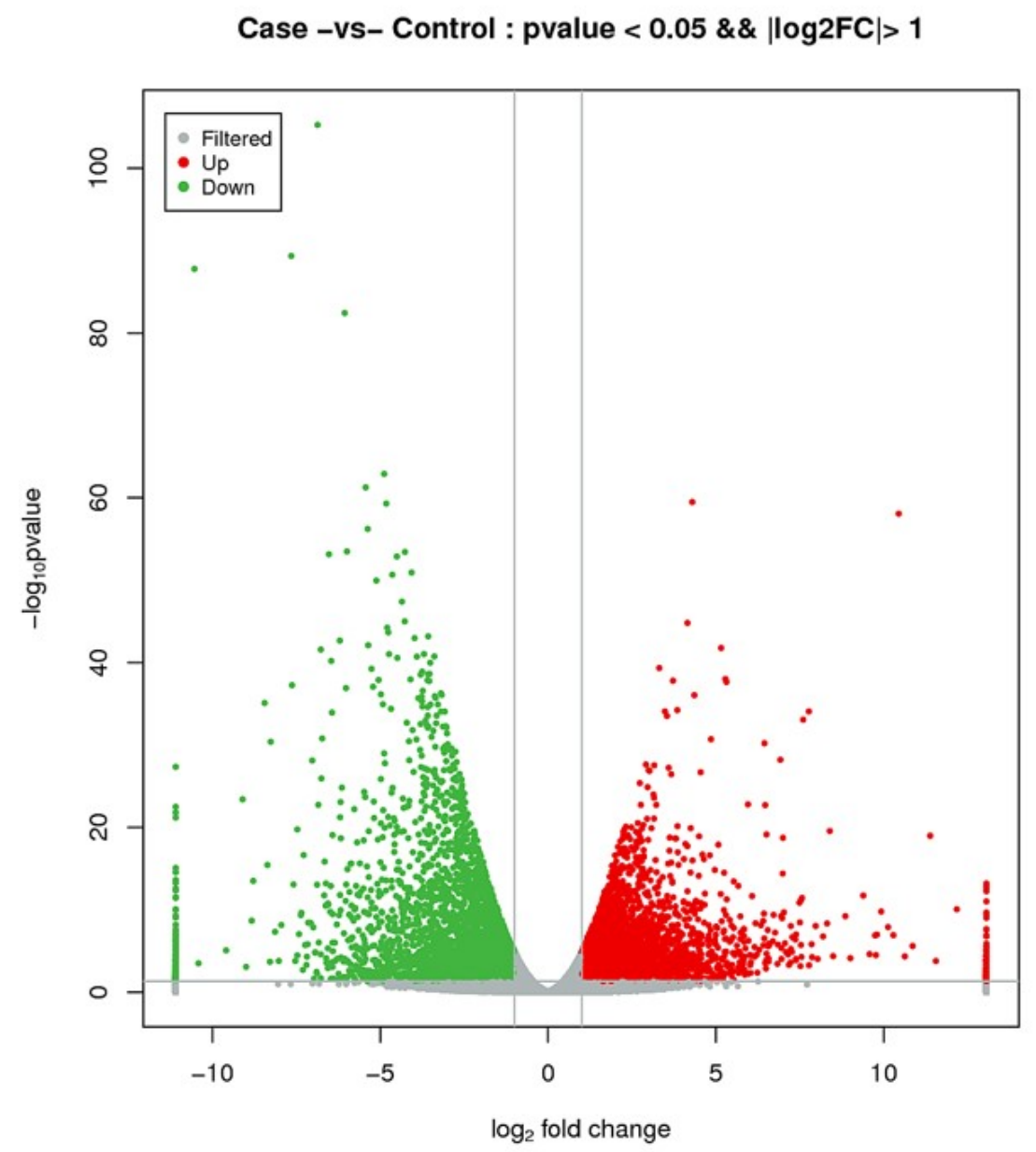




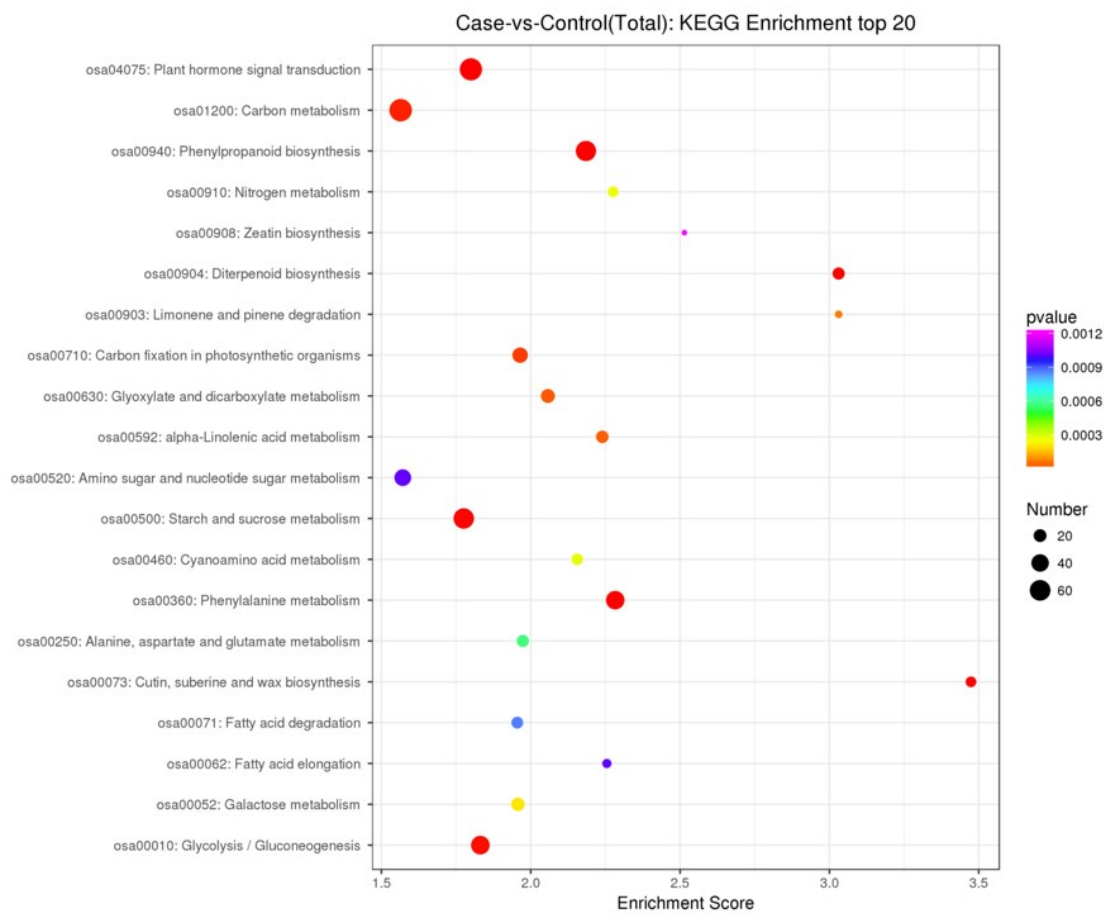

a

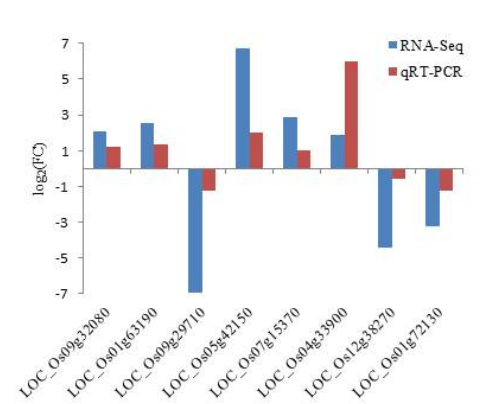

c

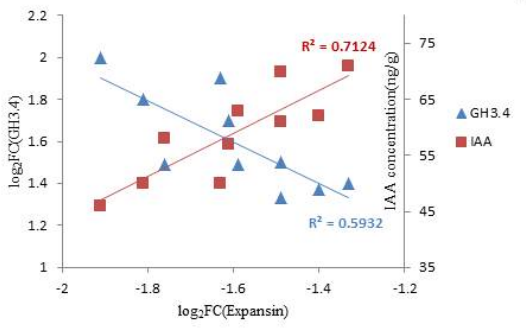

b

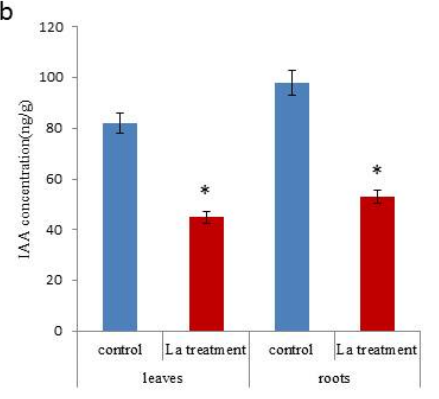

d

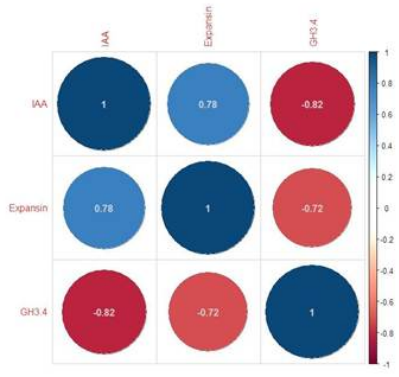




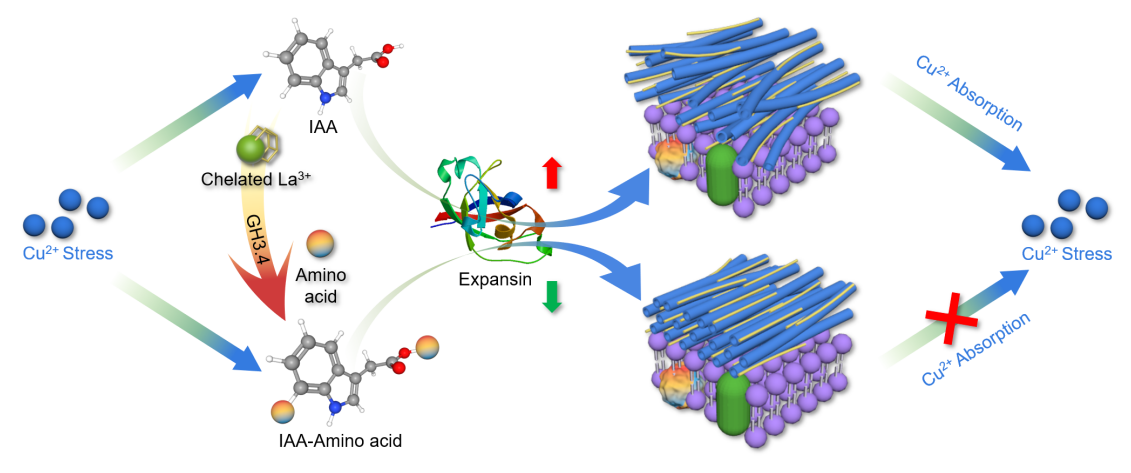

